\title{
Intradural Anomalies in Scoliosis
}

\section{Iqroop Chopra}

\section{ABSTRACT}

Whole spine magnetic resonance imaging screening is now mandatory before scoliosis correction surgery. Craniovertebral junction, such as Chiari malformation is tackled earlier as a staged procedure before the scoliosis procedure whereas tethering and diastematomyelia can be undertaken at the same time as the scoliosis correction.

Keywords: Chiari malformation, Diastematomyelia, Detethering, Intradural anomalies, Scoliosis.

How to cite this article: Chopra I. Intradural Anomalies in Scoliosis. J Postgrad Med Edu Res 2017;51(2):55-57.

\section{Source of support: Nil}

\section{Conflict of interest: None}

\section{INTRODUCTION}

The risks of neurological complications associated with scoliosis correction surgery are well-documented. The free availability of magnetic resonance imaging (MRI) scanning has made it a mandatory preoperative investigation. A whole spine MRI is now a protocolled investigation to screen for intradural anomalies. If there is a positive finding, the patient needs to be further investigated with a cranial MRI. ${ }^{1}$

The anomalies associated with scoliosis are:

- Intracranial

- Hydrocephalus

- Neuroepithelial cysts

- Craniovertebral (CV) junction

- Cerebellar ectopia

- Chiari malformations

- Spinal

- Syringomyelia

- Tethered cord/filum tumors

- Diastematomyelia/diamyelia

- Tumors

- Vascular lesions

Clinical Lead

Department of Trauma and Orthopedics, University Hospital of Wales, Cardiff, Wales, United Kingdom

Corresponding Author: Iqroop Chopra, Consultant Spinal Neurosurgeon, Department of Trauma and Orthopedics University Hospital of Wales, Cardiff, Wales, United Kingdom Phone: +442920715289, e-mail: ichopra@doctors.org.uk

\section{INCIDENCE}

Due to simultaneous intrauterine development of various organs, several syndromes are associated with vertebral anomalies. These may vary from no associated organ involvement to multiple organ developmental pathologies.

The VACTERL syndrome consists of vertebral defects, anal atresia, cardiac anomalies, tracheoesophageal fistula with esophageal atresia, radial and renal dysplasia, and limb bud anomalies. Vertebral anomalies are seen in 70\% of cases whereas spinal dysraphism with tethered cord is a less common finding.

Rajasekaran et $\mathrm{al}^{2}$ looked at 177 scoliosis patients in the pediatric population with a cut-off age at 21 years. In congenital scoliosis, just over one-third had intraspinal amomalies, such as tethered cord with their incidence increasing in patients who had multiple vertebral skeletal problems. In idiopathic scoliosis, the commonest anomaly was a Chiari malformation with or without syringomyelia. The presence of early onset, neurodeficit, and atypical kyphosis increased the chances of finding a positive MRI finding. Scoliosis secondary to neurofibromatosis, neuromuscular, and connective tissue disorders had just under a quarter with intradural findings.

\section{INVESTIGATIONS}

Once the diagnosis of scoliosis is established and scoliogram films support operative intervention, the workup should include a whole spine MRI scan to rule out intradural anomalies. If a Chiari malformation is picked up, brain MRI scans is required to look at associated intracranial anomalies (hydrocephalus, cysts or tumors). If syringomyelia is present, a contrast-enhanced spinal MRI is performed to rule out an associated spinal cord tumor. A cine MRI to establish flow around the CV junction in cerebellar ectopia has limited diagnostic and prognostic value. Associated bony anomalies, such as basilar invagination, atlanto-occipital assimilation and fusion, congenital spinal stenosis, diastematomyelia, hemivertebrae, spina bifida, and Klippel-Feil deformity can be defined on plain films and reformatted computed tomography (CT) scans. There is little role for a CT myelography.

\section{CHIARI MALFORMATION}

Cleland first reported on cases of cerebellar ectopia but it was the Austrian pathologist Hans Chiari who described 
and classified the condition. His anatomist colleague Julius Arnold elaborated on the type II so that is called Arnold-Chiari malformation (ACM). The last type was added later to the original classification. ${ }^{3}$

Type I: This is described as the peg like elongation or herniation of the tonsils $>4 \mathrm{~mm}$ below the level of the foramen magnum compromising the space available to the medulla oblongata into the spinal canal.

Type II: This is the classical ACM with caudal displacement of the vermis, medulla, and pons. It is not unusual to have elongation or kinking of the brain stem with effacement of the fourth ventricle.

Type III: The major part of cerebellum is herniated through a bony defect or into the spinal canal.

Type IV: Cerebellar hypoplasia or aplasia was a later addition to the classification.

Other MRI findings associated with Chiari malformation in the pediatric population are compromise of the basal subarachnoid spaces, overcrowding in the posterior fossa, peg shaped tonsils, medullary kinking, small volume of the posterior fossa, increased slope of the tentorium, and basilar impression. ${ }^{4}$

Symptomatology may vary with a sizeable population being picked up on MRI screening before scoliosis surgery to pressure headaches, electric sensation down the arms on neck flexion (L'hermitte's sign), facial pain, hand grip weakness, Horner's syndrome, and occasionally respiratory symptoms.

Surgery is usually undertaken a few months before the corrective scoliosis surgery. The aim of the surgery is to make room at the $\mathrm{CV}$ junction by bony decompression and, if required, duraplasty with or without tonsillar shrinkage. The positioning is prone with the head fixed in Mayfield pins, flexed, and pushed posteriorly to open the space between the occiput and the upper cervical spine. The skin incision runs from bony prominences of the occipital protuberance to the $\mathrm{C} 2$ spinous process. The posterior fossa and the posterior arch of $\mathrm{C} 1$ are exposed with a T-shaped muscle strip. The bony decompression involves removal of the foramen magnum posterior lip along with the $\mathrm{C} 1$ posterior arch. This exposes the dura along with a transverse band at the $\mathrm{CV}$ junction, which needs to be excised. An arachnoid sparing Y-shaped durotomy may be carried out. Adequate decompression of the intradural structures can be visualized and this can be confirmed by placing an ultrasound probe over the exposed meninges. If, due to adhesions, the cerebrospinal fluid (CSF) egress is compromised then adhesiolysis with excision of the cerebellar tonsils may need to be carried out. The Y-V duraplasty is then carried out (Fig. 1). ${ }^{5}$

Although not included in the nomenclature, Chiari malformation is frequently seen with syringomyelia.

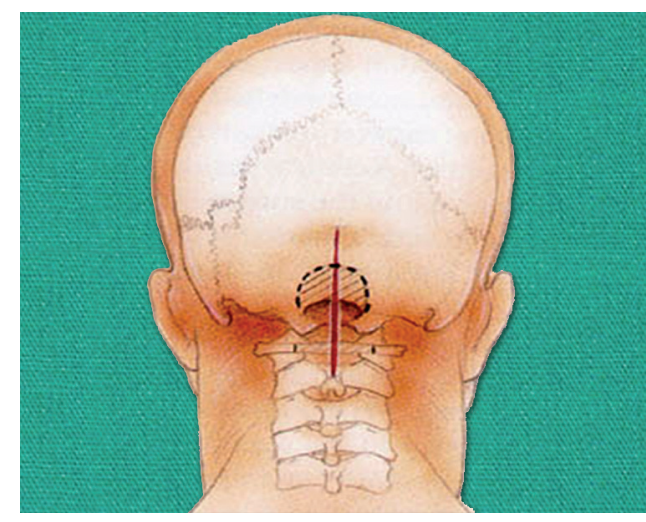

Fig. 1: The skin and bony landmarks of foramen magnum decompression

\section{SYRINGOHYDROMYELIA}

Syringohydromyelia is fluid-filled tubular cyst (syrinx) within the central, usually cervical spinal cord. The syrinx may enlarge and expand into the grey and then white matter. The buildup of fluid pressure compresses the anterior horn cells and subsequently the nervous tissue of the corticospinal and spinothalamic tracts. ${ }^{6}$

Adams and Victor ${ }^{1}$ classified dilatation of the spinal canal into:

- Hydromyelia

- FM anomalies

- Basal anomalies

- Syringomyelia

- SC injury

- Arachnoiditis

- Tumor

- Idiopathic

Symptoms may vary from being nonspecific, including pain, weakness, and stiffness in the back, shoulders, arms, or legs to specific loss of sensation for heat and cold, especially in the hands. Damage to tracts around the central canal may lead to bowel, bladder, and sexual dysfunction.

Treatment includes

- Foramen magnum decompression reduces compression around the CV junction and re-establishes CSF flow help drain the cervical syrinx. Whether duraplasty after bony decompression helps in drainage of the cyst is unclear. Durham et al in their national institute for health and care excellence recommended the children with Chiari malformation type I, posterior fossa decompression with duraplasty had a lower risk of reoperation but higher risk of postoperative cerebrospinal fluid related complications than posterior fossa decompression alone.

- Terminal ventriculostomy is useful in conus syrinx with a tethered cord, where detethering will drain the cyst into the subarachnoid space. 
- Direct drainage procedures include Syringotomy with or without using a flexible endoscope, or diverting the trapped fluid through a Syringo-subarachnoid shunt, Syringo-pleural shunt, or Syringo-peritoneal shunt.

\section{SPINA BIFIDA}

- Tethered/low-lying cord

- Dysraphism

- Diastematomyelia

- Diplomyelia

- Spina bifida occulta

- Hemangioma

- Tuff of hair

- Skin tether (dimple)

- Dermal sinus

- Lipoma

- Syringomyelia

\section{TETHERED/LOW-LYING CORD}

Reimann and Anson ${ }^{7}$ in an autopsy study underlined that in $95 \%$ of normal adults, the spinal cord terminates at or above the inferior aspect of L2. In classical tethered cord, the conus medularis is low-lying but there is good evidence in literature to suggest that tethered cord may occur in presence of normal positioning of the conus. The frequency of other bony, neurological, or cutaneous anomalies is much smaller when the conus ends above L2. Bladder dysfunction is an early symptom although a sizeable population maybe asymptomatic. When scoliosis correction is considered, detethering should be considered before correction. This should ideally be done in the same sitting before the corrective procedure is carried out.

Surgery is performed with the patient prone and exposing the L5 and S1 posterior elements. A laminectomy is carried out and the dura opened in the midline. The dura is held open with stay sutures. At this point, the filum terminale is identified as a thickened, taunt ligament lying posterior, and in the midline as compared to the nerve roots, which exit anterolaterally through their dural sleeves. There are usually blood vessels on the filum. The sacral nerves, which innervate the bladder and the perianal area, need to be isolated and held away with a cottonoid. The isolated filum is confirmed by stimulating with a monitoring probe, the electrodes positioned preoperatively into the anal sphincter. Once confirmed, the filum is clipped, cauterized with a diathermy, and cut. It is not unusual to see the proximal cut part of the filum to retract cranially. The dura is then closed and the scoliosis corrective procedure carried out in the same sitting. Gracés-Ambrossi et $\mathrm{al}^{8}$ concluded that the rate of symptomatic improvement was greatest for pain resolution, followed by motor, and then urinary improvement.

\section{DIASTEMATOMYELIA/DIPLOMYELIA}

Diastematomyelia is a congenital anomaly, often associated with spina bifida, in which the spinal cord is split into halves by a bony spicule or fibrous band, each half being surrounded by a dural sac, whereas diplomyelia is a true duplication of spinal cord in which there are two hemicords with two pairs or anterior and posterior nerve roots sharing a single subarachnoid space. The embryological origin is poorly understood and is associated with spina bifida, hemivertebra, block vertebra, and kyphoscoliosis. Dilpomyelia may not be symptomatic unless associated with a tethered cord or syringomyelia. ${ }^{9}$

Symptoms may vary from being asymptomatic thorough mid and lower back pain to progressive neurological deficit, which includes subtle autonomic symptoms, weakness in lower limbs, and incontinence of urine.

Surgery is indicated when the cord is tethered either at the conus or at the level of the spur, specially so when there is neurological deficit which is progressive. In asymptomatic patients, the intradural procedure may be performed at the same sitting as that of scoliosis correction. Surgical intervention includes removal of the fibrous or bony spur followed by detethering of the cord or hemicords. If the split cord reforms distal to the spur, the two dural tubes are opened and duraplasty carried out to convert it into a single thecal sac.

\section{REFERENCES}

1. Victor, M.; Ropper AH. Diseases of the spinal cord. In: Principles of neurology. USA: McGraw-Hill Professional, 2000 Dec; pp. 1692.

2. Rajasekaran S, Kamath V, Kiran R, Shetty AP. Intraspinal anomalies in scoliosis: An MRI analysis of 177 consecutive scoliosis patients. Indian J Orthop 2010 Jan;44(1):57-63.

3. Milhorat TH, Chou MW, Trinidad EM, Kula RW, Mandell M, Wolpert C, Speer MC. Chiari I malformation redefined: clinical and radiographic findings for 364 symptomatic patients. Neurosurgery 1999 May;44(5):1005-1017.

4. Mikulis DJ, Diaz O, Egglin TK, Sanchez R. Variance of the position of the cerebellar tonsils with age: preliminary report. Radiology 1992 Jun:183(3):725-728.

5. Durham SR, Fjeld-Olenec K. Comparison of posterior fossa decompression with and without duraplasty for the surgical treatment of Chiari malformation Type I in pediatric patients: a meta-analysis. J Neurosurg Pediatr 2008 Jul;2(1): 42-49.

6. Anson, JA.; Benzel, EC.; Awad IA. Syringomyelia and the Chiari malformations. USA: Thieme Medical Publishers; 1997; pp. 59-62.

7. Reimann AF, Anson BJ. Vertebral level of termination of the spinal cord with report of a case of sacral cord. Anat Rec 1944;88:127-138.

8. Garcés-Ambrossi GL, McGirt MJ, Samuels R, Sciubba DM, Bydon A, Gokaslan ZL, Jallo GI. Neurological outcome after surgical management of adult tethered cord syndrome. J Neurosurg Spine 2009 Sep;11(3):304-309.

9. Proctor MR, Scott RM. Long-term outcome for patients with split cord malformation. Neurosurg Focus 2001 Jan; 10(1):e5. 